\title{
IS CANNABIS USE RELATED TO ROAD CRASHES? A STUDY OF LONG DISTANCE COMMERCIAL DRIVERS IN NIGERIA
}

\author{
Victor Olufolahan Lasebikan
}

Department of Psychiatry, University College Hospital, Ibadan, Nigeria

\begin{abstract}
Factors associated with driving under the influence of cannabis (DUIC) and related road crashes among 422 commercial drivers were studied. A multivariate analysis was conducted to understand the associations between risk factors and DUIC and car crashes respectively. Young age, OR $=3.6$, 95\% CI 1.9-7.6; cannabis abuse, $\mathrm{OR}=4.1,95 \% \mathrm{CI}, 1.9-8.2$; cannabis dependence, $\mathrm{OR}=4.4,95 \%$ CI, 2.1 - 7.8; hire- driver, $\mathrm{OR}=5.3,95 \% \mathrm{CI}, 2.0-14.2$, remained associated with DUIC after model adjustments while previous DUIC accidents, OR $=4.5,95 \%$ CI, $2.2-11.0$; combined DUIC and driving under influence of alcohol (DUIA), $\mathrm{OR}=5.1,95 \% \mathrm{CI}, 2.7-14.0$, remained associated with cannabis related crashes after model adjustment. DUIC increases the risk of involvement in a crash most particularly if there is associated DUIA.
\end{abstract}

KeY WoRDs: Cannabis, driving under influence, Nigeria, road crashes, commercial drivers

\section{INTRODUCTION}

Epidemiological studies have often focused on responsibility for a crash; results have varied with respect to the increase in responsibility attributable to cannabis consumption (Gerberich et al 2003; Dussault et al 2002; Brault et al 2004; Mura et al 2003). Several cannabis smokers have reported to have driven inebriated with cannabis (Albery, et al 2004; Alvarez et al, 2007). Although the worst driving impairment is found 20 to 40 minutes after smoking, and people are usually back to normal 2.5 hours later, the underlying difficulty is in the absence of a synchronous relation between a change in behaviour and the presence of cannabinoids in the blood or urine (Huestis et al, 1992).
Although a good proportion of those suspected as being clinically impaired have elevated blood level of tetrahyrocannabinol (THC) (Jones et al, 2008; Augusburger et al, 2005; Khiabani et al, 2007), Robbe (as cited in Sexton et al, 2000) reported that most stoned drivers don't seem particularly impaired on actual road tests. Experienced smokers who drive on a set course show almost no impairment under the influence of cannabis--except when it is combined with alcohol (Sutton, 1983).

The relationship between cannabis use and car crash is controversial. Studies have found increased risk of crash as a result of cannabis use (Gerberich et al 2003; Dussault et al 2002; Brault et al 2004; Mura et al 2003). The odds

Corresponding author: Dr Victor Olufolahan.Lasebikan MB CHB, B Sc Hons (Health Sc), MPH, PhD, FWACP (Psych), Department of Psychiatry, University College Hospital, PMB 5116, Ibadan, Nigeria Ibadan.Email victorlash@yahoo. com/victorlasebikan@yahoo.co.uk,Tel: +234 80 60733382/+2348075033855 
of having a cannabis related crash increases when combined with alcohol (Mura et al 2005). In contrast, Movig et al (2004) reported no meaningful association between smoking cannabis and crashing. Rather, it actually decreases the risk (Everett et al 1999; Fergusson et al 2003; Vassallo et al, 2008, Gmel et al, 2009). There are increasing evidences that cannabis use alone is not a risk factor for car crash, (Jones et al 2005; Bedard et al 2007). One simulator study and two on-road studies found that cannabis smokers tend to increase the distance between themselves and the car in front of them. (Robbe \& O'Hanlon, 1993). Other studies have found that cannabis use does not impair sign detection (Khiabani et al 2006), a sudden lane-changing task, (Lowenstein et al, 2001) or detecting and responding to hazardous events (Augsburger et al, 2005).

Some researchers have suggested that the increased risk of crashing by stoned drivers is because of the "characteristics of the young people who used cannabis rather than the effects of cannabis use on driver performance" (Blows et al 2005).

In Nigeria, the problem of cannabis use became worrisome post Second World War. This was because of the return of the soldiers with some seeds of cannabis sativa, which with time, the cultivation led to trafficking and abuse of the cannabis plant (National Drug and Law Enforcement Agency [NDLEA] 2009). Thus, Nigeria's profile of drug use and abuse is characterized by widespread and an estimated lifetime consumption of cannabis of $10.8 \%$ of which commercial drivers and other motor park operatives are vulnerable (United Nation's Office on Drug and Crime [UNODP] 2007). Lasebikan (1997), reported a past year cannabis use rate of $44.5 \%$ and an accident rate of $19.2 \%$ in Ibadan, Oyo State among commercial drivers. Among those drivers plying Lagos- Ibadan expressway in Shagamu, Ogun State, Adenekan and Osibogun, (1999) also reported a past year cannabis use rate of $30.1 \%$ and accident rate of $33.9 \%$. Similar high rate was reported in Ilorin Kwara state (Makanjuola et al, 2007). Several case-control and culpability studies contradict each other about cannabis use and auto- crash, hence justification for this study.

The objective of the study was to evaluate the prevalence and risk factors of driving under the influence of cannabis (DUIC)/stone driving, including cannabis related crashes in past year among long distance commercial drivers. It was hypothesized that driving under influence of cannabis (DUIC) and cannabis related crashes would be commoner among hire drivers.

\section{METHOD}

\section{Study Area}

This report is a part of a Nigerian Survey on Alcohol and Drug Use among commercial drivers. Data were collected between January 2009 and July 2009 from drivers plying 4 regions in Nigeria, namely North, East, Middle Belt and Far West/Across Nigeria Border. The study area was Ibadan, Oyo state, Nigeria. The city is located in the southwestern part of the country, with a population of about 3.8 million people (Mongabay.com).

\section{Sampling Procedure}

All the 16 inter-states motor parks in Ibadan were stratified into four groups according to their farthest destination: namely to the North, Middle Belt, Eastern region, Far West/Across the Border. The motor parks whose drivers did not fulfill the criteria for "long distance" (final destination less than $500 \mathrm{~km}$ from port of embarking) were deleted from each group. A motor park was randomly selected from each of the groups by balloting. Six hundred and sixteen drivers were invited to participate in the study. However, 194 dropped out of the study for various reasons including ill health and deaths. Thus, 214 were interviewed from Ojoo (first Motor Park), 98 from Sango (second motor park), 98 from new garage (third motor park) and 12 from Academy (forth motor park) respectively. In all, 422 drivers were interviewed. In each of the study parks, the drivers were listed by their names and were given tallies in 
order to prevent duplicating of response. The first driver in each motor park was chosen by simple random sampling. Written informed consent was obtained from each participant and Ethical Review Committee of the Oyo state Ministry of Health, Ibadan in January 2009. Information obtained from the drivers was confidential and each subject's anonymity preserved. Face-to-face interviews which lasted for an average of 43 minutes were conducted in the respondents' motor park.

\section{Measures}

Two questionnaires were used in this study.

1. Socio-demographic questionnaire: This asked for information on sociodemographic characteristics such as age, sex, religion, marital status, occupation, duration of stay in Motor Park, status of driver, first choice of alcohol beverage, smoking place for example (Motor park, bar, a friend's house, relatives etc).

2. The Composite International diagnostic interview (CIDI, WHO, 1998)

The drug and alcohol sections of the Composite International Diagnostic Interview was used, thereafter, a computer program CIDI auto was used to obtain lifetime and current ICD10/DSM IV diagnoses. The CIDI auto is software that concurrently generates both ICD 10 and DSM IV diagnoses using various indices such as physical, psychological and social health problems.

Outcome: Driving under influence of cannabis (DUIC) was defined as driving under the influence of Cannabis or suffering from its aftereffects that increased the chances of getting hurt- for instance when driving a motor vehicle.

Risk factors associated with DUIC: these were obtained by means of the following questions: Smoking place: "Think about the most recent occasion when you drove after smoking cannabis, where did you smoke in that occasion? Please show in the respondent card the place that best describes where you smoked
(Motor park, bar, a friend's house, joint etc.)". Combined DUIC and DUIA: Do you drive immediately after taking at least 5 drinks in addition to smoking cannabis?

Passenger's comment: "How many times has a passenger accused you to have been driving under influence?"

A focus group discussion also generated an opinion score: the following issues were discussed: " a driver caught by the police after smoking cannabis should be A) sent to prison; B) should have his license suspended; C) a driver caught by the police after taking cannabis should have to pay fines". Answers were dichotomized (positive if the answer was "in the majority of times" or "always", and negative if the answer was "never" or "in few or limited situations". Individuals with two or three positive responses were classified as having a "favorable opinion toward the policies"; individuals with zero or one positive response were classified as "unfavorable opinion"; favorable opinion was used as the reference category for analyses.

Punishment: to assess how subjects perceived the possibility of DUIC punishment, the following question was asked: "If a person drives after taking cannabis, it is certain that a police officer is going to stop and arrest him". Answers were dichotomized (positive if the answer was "totally agree" or "partially agree", and negative if the answer was "don't agree" or "disagree".

\section{ANALYSIS}

Data were weighted to adjust for the probability of selection into the sample. Post-stratification weights were calculated to adjust the sample to known population distributions on certain demographic characteristics (age and region of final destination of driver). All analyses were performed with the SPSS - version 13. Initially, bivariate analyses compared hire drivers in terms of sociodemographic variables, frequency of use, lifetime and current user. Other variables studied included DSM cannabis abuse, DSM cannabis dependence, 
multiple diagnoses, passenger's comments of a stoned and also cannabis related accidents.

For multivariate risk analysis of DUIC and cannabis related road crashes respectively, variables that were significant during bivariate analysis were entered into the model of the logistic regression equation. Variables were entered in the binary form, i.e. 0,1 , and were coded in a way to illustrate the effect of each level. To facilitate the interpretation of odds ratio, a reference category was always chosen for the independent variables with which other variables could be compared.

\section{RESULTS}

The overall Lifetime prevalence of cannabis was $55.7 \%$, prevalence rates of current abuse $44.5 \%$, self reported DUIC $38.4 \%$ and cannabis related crashes $8.5 \%$. The sample of 422 subjects comprised of $316(74.9 \%)$ drivers with unexpired driver's license, whose mean age was $39.3 \pm 13.6$ years, median 37 years. Hire-drivers tended to be younger, with expired driver's license, with low level of schooling, with current DSM diagnoses of alcohol abuse and dependence, reported higher prevalence of DUIC, higher prevalence of DSM cannabis abuse or dependence, higher prevalence of additional DSM most commonly alcohol abuse or dependence, higher prevalence of cannabis related crashes in past year. Their route was also more likely to be North-South of Nigeria (Table 1).

Tables 2 and 3 show analyses of demographic variables and those of behaviors related to cannabis, after the final model obtained through multivariate logistic regression analysis. Young age (24-34years), $\mathrm{OR}=3.6,95 \% \mathrm{CI}$ 1.9-7.6; DSM IV diagnosis of cannabis abuse, $\mathrm{OR}=4.1,95 \% \mathrm{CI}, 1.9-8.2$; DSM IV diagnosis of cannabis dependence, $\mathrm{OR}=4.4,95 \% \mathrm{CI}$, 2.1- 7.8; being a hire driver, $\mathrm{OR}=5.3,95 \%$ CI, 2.0- 14.2, remained associated with DUIC after model adjustments.

Educational level, distance of final destination $\geq 500 \mathrm{Km}$, the perception of punishment, critical comments from passengers about
DUIC and previous DUIC accidents were not risk factors for driving after stoning. In terms of cannabis related car crashes, previous DUIC accidents, OR $=4.5,95 \%$ CI, $2.2-11.0$; dual DUIC and DUIA, OR $=5.1,95 \%$ CI, $2.7-$ 14.0; dual diagnosis of a cannabis abuse or dependence with alcohol abuse or dependence, $\mathrm{OR}=7.2,95 \% \mathrm{CI}, 3.4-31.6$, remained associated with cannabis related car crashes after model adjustment.

\section{DISCUSSION}

This study that evaluated the prevalence of reported DUIC and risk behaviors in a sample of drivers originated from a representative sample of the Nigerian Commercial drivers is unique. Although there have been few prior studies about this topic in Nigeria (Oladepo \& Breiger, 1986; Lasebikan,1997; Adenekan \& Osibogun, 1999), the use of structured interviewing instrument (the CIDI) had made some constructs in this paper to based on clearly defined diagnostic categorizations. The risk of responsibility for fatal traffic crashes while driving under the influence of cannabis although there is an association has not shown a causal relation between cannabis and crashes.

The increased fatality risk of drivers under the influence of cannabis is a phenomenon that deserves further investigation. The vehicular crashes reported in this study could partly be explained by greater exposure of the drivers via riskier behaviour such as not wearing seat belts, or socio-economic disparities such as the age of their vehicle (Assailly \& Biecheler as cited in Laumon et al, 2005), and partly by a reduced ability to avoid a crash, (Laumon et al, as cited in Laumon et al, 2005). However, the description of characteristics of individuals who are saddled with public commuting i.e. commercial hire- drivers who are subject to driving under influence of cannabis, is an important epidemiologic tool. These data can help identify which type of population groups would potentially be targeted for focused preventive interventions. The higher prevalence rate of cannabis abuse among hire-drivers is in line with the report 
Table 1. Comparisons between Hired and Owner Driver

\begin{tabular}{|c|c|c|c|}
\hline Variable & $\begin{array}{c}\text { Hire -Driver } \\
\text { Yes (\%) } \\
n=351\end{array}$ & $\begin{array}{c}\text { Owner - Driver } \\
\text { No (\%) } \\
\mathbf{n}=71\end{array}$ & p value \\
\hline \multicolumn{4}{|l|}{ Age } \\
\hline$<25$ & - & - & $<0.001$ \\
\hline $25-34$ & 28.8 & 2.8 & \\
\hline $35-44$ & 26.2 & 14.1 & \\
\hline $45-54$ & 25.1 & 33.8 & \\
\hline$>54$ & 19.9 & 49.3 & \\
\hline \multicolumn{4}{|l|}{ Education } \\
\hline No formal & 4.6 & 7.0 & $<0.001$ \\
\hline Primary complete/incomplete & 39.9 & 52.1 & \\
\hline Secondary complete/incomplete & 45.6 & 64.8 & \\
\hline College complete/incomplete & 4.3 & 4.3 & \\
\hline \multicolumn{4}{|l|}{ Marital Status } \\
\hline Currently married & 71.1 & 90.1 & 0.001 \\
\hline Not currently married & 28.5 & 9.9 & \\
\hline \multicolumn{4}{|l|}{ Route } \\
\hline North-South & 58.1 & 15.5 & $<0.001$ \\
\hline Middle belt -South & 23.4 & 22.5 & \\
\hline East-South & 15.4 & 62.0 & \\
\hline Across border-south & 3.1 & 1.4 & \\
\hline Unexpired license & 72.4 & 87.3 & 0.01 \\
\hline \multicolumn{4}{|l|}{ Frequency of current use } \\
\hline Almost everyday & 31.1 & 1.3 & $<0.001$ \\
\hline 3-4 days a week & 51.2 & 16.4 & $<0.01$ \\
\hline$<3$ days a week & 17.7 & 72.3 & $<0.001$ \\
\hline \multicolumn{4}{|l|}{ Age of use onset } \\
\hline$<15$ & 8.7 & 9.0 & 0.9 \\
\hline $16-17$ & 43.2 & 45.6 & 0.8 \\
\hline$>18$ & 48.1 & 45.4 & 0.9 \\
\hline \multicolumn{4}{|l|}{ Single diagnosis } \\
\hline Lifetime cannabis abuse & 30.4 & 25.3 & 0.7 \\
\hline Current cannabis abuse* & 21.5 & 1.5 & $<0.001$ \\
\hline Lifetime cannabis dependence & 6.7 & 5.0 & 0.09 \\
\hline Current cannabis dependence & 3.6 & 2.0 & 0.07 \\
\hline \multicolumn{4}{|l|}{ Multiple Diagnoses } \\
\hline $\begin{array}{l}\text { Current cannabis abuse }+ \text { alcohol abuse } \\
\text { or dependence* }\end{array}$ & 12.0 & 1.2 & $<0.001$ \\
\hline $\begin{array}{l}\text { Current cannabis dependence }+ \\
\text { alcohol abuse or dependence * }\end{array}$ & 1.1 & - & - \\
\hline $\begin{array}{l}\text { Self reported DUIC } \\
\text { Passenger had suspected DUIC** }\end{array}$ & $\begin{array}{l}27.2 \\
17.2\end{array}$ & 11.2 & 0.04 \\
\hline Cannabis related RTA & 7.9 & 0.6 & $<0.001$ \\
\hline
\end{tabular}

Recency- *within 2 weeks, ** in past year; b hired drivers $n=314$ owner drivers $n=10$ 
Table 2. Risk Factors Associated with Driving Under Influence of Cannabis ( $\mathrm{n}=422)$

\begin{tabular}{|c|c|c|c|c|c|c|}
\hline $\begin{array}{l}\text { Variable } \\
\text { OR }\end{array}$ & $\begin{array}{l}\text { Unadjusted } \\
95 \%(C I) * *\end{array}$ & $\bar{P}$ & $\begin{array}{l}\text { Adjusted OR } \\
95 \%(C I) * *\end{array}$ & $\bar{P}$ & B & $\mathrm{SE}^{* * * 95 \%(\mathrm{CI})}$ \\
\hline Age- 24-34 & $9.2(2.2-9.1)$ & 0.01 & $3.6(1.9-7.6)$ & 0.04 & 1.22 & $0.09(0.03-1.32)$ \\
\hline Education a & 0.64 & & & & & \\
\hline $\begin{array}{l}\text { At least some secondary } \\
\text { Education }\end{array}$ & $1.1(0.3-2.2)$ & 0.09 & & & & \\
\hline $\begin{array}{l}\text { At least some College } \\
\text { Education }\end{array}$ & $1.2(0.5-2.0)$ & 0.09 & & & & \\
\hline College education & 1 & & & & & \\
\hline DSM cannabis abuse & $4.9(2.1-7.6)$ & 0.02 & $4.1(1.9-8.2)$ & 0.01 & 0.59 & $0.04(0.02-1.42)$ \\
\hline $\begin{array}{l}\text { DSM cannabis } \\
\text { dependence }\end{array}$ & $6.4(3.7-11.2)$ & $<0.01$ & $4.4(2.1-7.8)$ & 0.01 & 0.78 & $0.50(0.07-0.42)$ \\
\hline Hired drivers status & $8.8(3.7-23.4)$ & 0.001 & $5.3(2.0-14.2)$ & $<0.01$ & 1.11 & $0.31(-160-0.20)$ \\
\hline $\begin{array}{l}\text { Mean distance covered } \\
\geq 500 \mathrm{~km} \text { at a stretch }\end{array}$ & $2.6(1.2-7.2)$ & 0.05 & $2.0(1.0-4.2)$ & 0.07 & 1.44 & $0.30(1.10-2.50)$ \\
\hline $\begin{array}{l}\text { Unfavorable opinion } \\
\text { score towards policies }\end{array}$ & $4.8(2.0-9.6)$ & 0.01 & $2.1(1.4-6.7)$ & 0.07 & 1.43 & $0.32(0.01-1.3)$ \\
\hline $\begin{array}{l}\text { Critical comments from } \\
\text { passengers about DUIA }\end{array}$ & $2.2(1.0-4.2)$ & 0.06 & $1.3(0.7-3.6)$ & 0.1 & 0.52 & $0.31(0.16-1.20)$ \\
\hline Previous DUIC accidents & $5.6(2.7-13.1)$ & $<0.001$ & $2.1(0.8-4.1)$ & 0.9 & 0.61 & $0.35(1.05-2.55)$ \\
\hline
\end{tabular}

a variable not included in the model, $* *$ Odds Ratio $95 \%$ confidence interval, $* * *$ standard error

Table 3. Risk factors associated with cannabis related road accidents

\begin{tabular}{|c|c|c|c|c|c|c|}
\hline Variables & $\begin{array}{l}\text { Unadjusted } \\
95 \%(C I) * *\end{array}$ & $\mathbf{P}$ & $\begin{array}{c}\text { Adjusted OR } \\
95 \%\end{array}$ & $\mathbf{P}$ & B & $\mathrm{SE}^{* * * 95 \%(\mathrm{CI})}$ \\
\hline $\begin{array}{l}\text { Intercept } \\
\text { Age- 24-34 }\end{array}$ & $4.0(2.0-8.6)$ & 0.01 & $1.9(0.9-3.1)$ & 0.09 & 1.22 & $0.05(0.03-1.12)$ \\
\hline Education ${ }^{\text {a }}$ & 0.64 & & & & & \\
\hline $\begin{array}{l}\text { At least some secondary } \\
\text { Education }\end{array}$ & $1.6(0.2-2.0)$ & 0.1 & & & & \\
\hline $\begin{array}{l}\text { At least some College } \\
\text { Education }\end{array}$ & $1.9(0.9-2.5)$ & 0.1 & & & & \\
\hline College education & 1 & & & & & \\
\hline DSM cannabis abuse & $4.8(2.2-11.4)$ & 0.02 & $2.5(1.5-4.0)$ & 0.06 & 0.56 & $0.42(0.03-1.44)$ \\
\hline $\begin{array}{l}\text { DSM cannabis } \\
\text { dependence }\end{array}$ & $3.3(1.8-6.9)$ & 0.04 & $2.2(1.7-3.1)$ & 0.07 & 0.72 & $0.53(0.01-0.65)$ \\
\hline Hired drivers status & $4.3(2.5-9.1)$ & 0.03 & $2.7(1.9-5.5)$ & 0.05 & 1.22 & $0.33(1.62-0.22)$ \\
\hline $\begin{array}{l}\text { Mean distance covered } \geq \\
500 \mathrm{~km} \text { at a stretch }{ }^{\text {a }}\end{array}$ & $2.4(1.4-3.0)$ & 0.07 & $2.5(1.5-4.5)$ & 0.07 & 1.16 & $0.35(1.15-2.55)$ \\
\hline $\begin{array}{l}\text { Unfavorable opinion score } \\
\text { towards policies a }\end{array}$ & $2.1(0.9-4.5)$ & 0.1 & $2.0(1.2-6.5)$ & 0.09 & 1.23 & $0.33(0.02-1.4)$ \\
\hline $\begin{array}{l}\text { Critical comments from } \\
\text { passengers about DUIC }\end{array}$ & $2.5(1.5-4.5)$ & 0.2 & $1.1(0.5-3.4)$ & 1.1 & 0.52 & $0.30(0.15-1.21)$ \\
\hline Previous DUIC accidents & $4.7(2.1-12.3)$ & $<0.001$ & $4.5(2.2-11.0)$ & $<0.001$ & 0.61 & $0.30(1.60-0.19)$ \\
\hline DUIC + DUIA & $9.6(2.7-31.3)$ & $<0.001$ & $5.1(2.7-14.0)$ & $<0.001$ & 0.59 & $0.29(1.52-2.65)$ \\
\hline $\begin{array}{l}\text { DSM cannabis abuse } \\
\text { or dependence }+ \\
\text { DSM alcohol abuse or } \\
\text { dependence }\end{array}$ & $8.9(2.3-18.5)$ & $<0.001$ & $7.2(3.4-31.6)$ & $<0.001$ & 0.78 & $0.30(1.60-0.19)$ \\
\hline
\end{tabular}


of Bankole (1999) during an interview with a cross section of Nigerian commercial drivers, commuters, police, road safety personnel, and officials of the drivers' union.

With regard to certain variables related to driving under influence of cannabis, age of first cannabis use, lifetime and current cannabis abuse or dependences, although there were certainly no differences between the two groups in terms of age of onset of use and also lifetime cannabis abuse or dependence, higher proportions of hire- drivers reported current abuse and dependence and multiple diagnoses of cannabis abuse or dependence with alcohol abuse or dependence and also higher prevalence of road accidents. This hire-drivers group also exclusively reported 'passengers had suspected driving under influence if cannabis'. The past year accident rate of $8.5 \%$ reported in this study is within range of what has been reported in other parts of the world (Dussault et al 2002; Gerberich et al 2003; Brault et al 2004; Mura et al 2005). It is unlikely that the prevalence of cannabis related crash found contributes to the high mortality rates due to traffic accidents in Nigeria as the multivariate risk analysis did not confirm this, especially among young commercial drivers particularly when associated with alcohol use and other risk factors are considered. Thus, direct association between cannabis use and fatal road accidents was is not objective.

However, the increased odds of having a cannabis related accident when a driver drove under the influence of both cannabis and alcohol or when a driver reported combined cannabis abuse or dependence with combined alcohol abuse or dependence is an important epidemiological finding. A potential explanation is that people who smoke cannabis share qualities with alcohol users--being young, male, and risk-taking--that would make them more likely to have car accidents even if they didn't smoke cannabis. For example, smoking cannabis goes along with speeding (Vassallo et al, 2008), drink driving, and not wearing a seatbelt (Everett et al 1999). Some researchers have suggested that there is a single factor--perhaps a "risky behavior" characteristic or "general driving problem" that underlies all risky driving behaviors, including driving stoned (Fergusson et al, 2003). If that's the case, then cannabis smoking while driving is a symptom, not a cause.

The confounding role of alcohol in crashes has also been highlighted. However, in terms of any interaction: consumption of both cannabis and alcohol could have only multiplied the risks related to consumption of either cannabis or alcohol alone, without specifically potentiating the effects of one by the other (INSERM, 2001).

The relation between opinion scores about policies on DUIC should not be ignored. Their opinion tend not to favor the punishment as only $16.9 \%$ of the sample was favorable to enforcement and punishment of offending drivers, this, even in the presence of generation of a strong support of society in the implementation of preventive and punishment measures may not be applauded by the drivers. As can be seen in table 2 , a negative "opinion score" (being unfavorable of enforcement and strict policies) seems not a risk factor for driving after stoning nor a risk factor for cannabis related car crashes. Also critical comments from passengers was not a risk factor for stone driving nor car crashes. This finding corroborates that of the focus group discussion in which the majority of the drivers believes that cannabis has driving enhancing characteristics.

In summary, commercial drivers plying various geopolitical zones of Nigeria, who were between ages 24 to 34 years, were hire drivers, with diagnoses of cannabis abuse or dependence seemed to have a higher odds of being associated with driving under influence of cannabis. Commercial drivers who drive under influence of both cannabis and alcohol, who had diagnoses of either cannabis abuse or dependence with either alcohol abuse or dependence seemed to have higher odds of reporting cannabis related car crashes in the past year.

This study has some limitations that must be addressed: a) all data analyzed were selfreported, which might underestimate the prevalence found. However, response rates of $68.5 \%$ demonstrated the willingness of the majority to take part in the study. Although 
alcohol was adjusted for, other drugs namely amphetamines, cocaine, and opiates were not adjusted for because of the small number of drivers who reported to be current users. This may suggest that these drugs are not a major issue in Nigeria at the moment. The inability to carry out any toxicological assessment including the breathalyzer was also another limitation for some current users with a few days of recency.

The study has highlighted that the risk of responsibility for road crashes while driving under the influence of cannabis should be interpreted with great caution as it appears that there is no causal relationship more so cannabis abuse or dependence were not risk factors for crashes. Although, the relationship between cannabis use and road accidents appears multiplied when cannabis is used in combination with alcohol, other risk factors for road accidents such as poor vehicle conditions, bad roads, non use of safety belts, indiscriminate mounting of road blocks by the police among others were not studied. This poses another limitation to the interpretation of the results.

Further work should include the share of all deaths attributable to the greater vulnerability of users under the influence of cannabis. This latter calculation was possible for drivers but is yet to be shown for other road users, namely passengers and pedestrians.

In order to obtain more reliable estimates of crashes attributable to cannabis or cannabis/ alcohol, commercial drivers should have toxicological assessments done before embarking on their journey.

\section{ACKNOWLEDGEMENTS}

Acknowledgement is given to Dr BVA Bello, the Director or Research Planning and Statistics and the Chairman of Epidemiological, Research and Ethical Review Committee of the Oyo state Ministry of Health, Ibadan for granting permission to undertake this study. Acknowledge is also given for the funding support of the New World Psychiatric Specialist Hospital, Ibadan,
Nigeria, Dr K. Adebayo (LAUTECH), Dr O Aremu (RRSH), Sola Ogundeji (NWSH) for providing support during data collection. This survey was carried out with the permission of the National Road Transport Workers Union. I thank the latter's coordinating staff both for their assistance and in ensuring the participation of their members.

\section{REFERENCES}

Adenekan A. K., \& Osibogun A. (1999). Drug use and road traffic accidents among commercial drivers and their assistants in Sagamu Ogun State. Journal of Community Medicine and Primary Health Care, 11, 36-47.

Alvarez F.J., Fierro I., \& Del Rio M.C. (2007). Cannabis and Driving: Results from a General Population Survey. Forensic Science International, 170, 111-116.

Albery I.P., Strang J, Gossop M, et al. (2005) Illicit Drugs and Driving: Prevalence, Beliefs and Accident Involvement Among a Cohort of Current Out-of-treatment Drug Users. Drug and Alcohol Dependence, 58:197-204.

Augsburger M, Donze N, Menetrey A, et al. (2005). Concentration of Drugs in Blood of Suspected Impaired Drivers. Forensic Science International, 153, 11-15.

Bankole N. (1999, September 7). Smooth ride to Grave. The Nigerian Tribune, $\mathrm{p} 4$.

Bedard M, Dubois S, Weaver B. (2007). The Impact of Marijuana on Driving. Canadian Journal of Public Health, 98:6-11.

Blows S, Ivers RQ, Connor J, et al. (2005). Cannabis Use and Car Crash Injury. Addiction (Abingdon, England), 100, 605-611.

Brault M, Dussault C, Bouchard J, et al. (2004) The Contribution of Alcohol and Other Drugs Among Fatally Injured Drivers in Quebec: Final Results. In: T2004: Paper presented at the 17th International Conference on Alcohol, Drugs and Traffic Safety, Glasgow, UK. Retrieved from http://www.madd.ca/english/research/ real_facts.pdf 
Dussault C, Brault M, Bouchard J, et al. (2002) The Contribution of Alcohol and Other Drugs Among Fatally Injured Drivers in Quebec: Some Preliminary Results. In16th International Conference on Alcohol, Drugs and Traffic Safety T2002 2002 Montreal, Canada. (pp. 423-430).

Everett SA, Lowry R, Cohen LR, et al. (1999) Unsafe Motor Vehicle Practices Among Substance-using College Students. Accident; Analysis and Prevention, 31, 667-673.

Fergusson D, Swain-Campbell N, Horwood J. (2003) Risky Driving Behaviour in Young People: Prevalence, Personal Characteristics and Traffic Accidents. Australian and New Zealand Journal of Public Health, 27, 337-342.

Gerberich SG, Sidney S, Braun BL, et al. (2003) Marijuana Use and Injury Events Resulting in Hospitalization. Annals of Epidemiology, 13, 230 -237.

Gmel G, Kuendig H, Rehm J, Schreyer N, Daeppen J (2009). Alcohol and cannabis use as risk factors for injury - a case-crossover analysis in a Swiss hospital emergency department. BMC Public Health 2009, 9:40.

Huestis M, Henningfield J, Cone E. (1992) Blood Cannabinoids. I. Absorption of THC and Formation of 11-OH-THC and THCCOOH During and After Smoking Cannabis. Journal of Analytical Toxicology;16:276-282.

Institut national de la santé et de la recherche médicale (INSERM) (2001). Cannabis Intoxication and Fatal Road

Crashes in France: population based casecontrol study. Retrieved from http://qkzz. net/article/340c1635-aa9d-4536-abc8e83f8d628cf5.htm

Jones C, Donnelly N, Swift W, et al. (2005). Driving Under the Influence of Cannabis: The Problem and Potential Countermeasures. Crime and Justice Bulletin, 87, 1-15. Retrieved from www.ndlerf.gov.au/ pub/Cannabis and driving.pdf

Jones AW, Holmgren A, Kugelberg FC (2008). Driving Under the Influence of Cannabis: A 10-Year Study of Age and Gender Differences in the Concentrations of Tetrahy- drocannabinol in Blood. Addiction, 103, 452-461.

Khiabani HZ, Bramness JG, Bjorneboe A, et al. (2006). Relationship Between THC Concentration in Blood and Impairment in Apprehended Drivers. Traffic Injury Prevention, 7, 111-116.

Lasebikan V.O (1997). Pattern of Psychoactive Substance use among Commercial drivers, Unpublished master's thesis). University of Ibadan, Nigeria.

Laumon B, Gadegbeku B, Martin JL, Biecheler MB (2005). Cannabis intoxication and fatal road crashes in France: population based case-control study. British Medical Journal, 331, 1371.

Lowenstein SR, Koziol-McLain J. (2001). Drugs and Traffic Crash Responsibility: A Study of Injured Motorists in Colorado. Journal of Trauma, 50, 313-320.

Makanjuola AB, Daramola TO, Obembe AO (2007). Psychoactive substance use among medical students in a Nigerian university. World Psychiatry, 6(2), 112-114.

Mongabay.com. Population of Ibadan. Retrieved from Http://population.mongabay. com/population/nigeria/2339354/ibadan

Movig KL, Mathijssen MP, Nagel PH, et al. (2004). Psychoactive Substance Use and the Risk of Motor Vehicle Accidents. Accident; Analysis and Prevention, 36, 631636.

Mura P, Kintz P, Ludes B, et al. (2003). Comparison of the Prevalence of Alcohol, Cannabis and Other Drugs between 900 Injured Drivers and 900 Control Subjects: Results of a French Collaborative Study. Forensic Science International, 133, 79-85.

National Drug Law Enforcement Agencies of Nigeria (2009). Brief History of Nigeria's Counter-Narcotic Efforts. Retrieved from http://www.ndlea.gov.ng/v1/?q=content/ history.

Oladepo and Brieger (1986) Road Traffic Accidents: Applying Brakes to a Killing Point. African Health, 30-32.

Robbe HWJ, O'Hanlon JF. (1993). Marijuana and Actual Driving Performance. Washington, DC: US Department of 
Transportation, National Highway Traffic Safety Administration. Retrieved from http://www.erowid.org/plants/cannabis/ cannabis_driving4.shtml

Sexton BF, Tunbridge RJ, Brook-Carter N et al (2000). The influence of cannabis on driving. Prepared for Road

Safety Division, Department of the Environment, Transport and the Regions. ISSN 0968-4107. TRL Limited. Retrieved from http://proxychi.baremetal.com/csdp.org/ research/TRL477.pdf
Sutton LR. (1983). The Effects of Alcohol, Marihuana and their Combination on Driving Ability. Journal of Studies on Alcohol, 44, 438-445.

United Nation's Office on Drug and Crime (2007). Drug Abuse. Retrieved from http:// www.unodc.org/nigeria/en/abuse.html.

Vassallo S, Smart D, Sanson A, et al. (2008). Risky Driving Among Young Australian Drivers II: Co-occurrence with Other Problem Behaviours. Accident; Analysis and Prevention, 40, 376-386. 